

\title{
Influence of formulation on friction properties of latex films
}

V. Divry, L. Jacomine, V. Le Houérou, Dominique Collin, C. Gauthier, Y. Holl

\section{To cite this version:}

V. Divry, L. Jacomine, V. Le Houérou, Dominique Collin, C. Gauthier, et al.. Influence of formulation on friction properties of latex films. Progress in Organic Coatings, 2017, 113, pp.189-199. 10.1016/j.porgcoat.2017.09.012 . hal-03497382

\section{HAL Id: hal-03497382 \\ https://hal.science/hal-03497382}

Submitted on 20 Dec 2021

HAL is a multi-disciplinary open access archive for the deposit and dissemination of scientific research documents, whether they are published or not. The documents may come from teaching and research institutions in France or abroad, or from public or private research centers.
L'archive ouverte pluridisciplinaire HAL, est destinée au dépôt et à la diffusion de documents scientifiques de niveau recherche, publiés ou non, émanant des établissements d'enseignement et de recherche français ou étrangers, des laboratoires publics ou privés. 


\title{
Influence of formulation on friction properties of latex films
}

\author{
V. Divry, L. Jacomine, V. Le Houérou, D. Collin, C. Gauthier, Y. Holl* \\ Université de Strasbourg \& Institut Charles Sadron CNRS UPR 22, 23, rue du Loess BP 84047, 67034 Strasbourg \\ Cedex 2, France
}

\begin{abstract}
Friction coefficients (called $\mu$ ) versus contact pressure or confinement (maximum indentation depth over film thickness) were measured together with bulk mechanical properties of waterborne, partially formulated, acrylic coatings. It was shown that the initial, unformulated latex film was significantly plasticized by humidity in air thanks to the presence of the acrylic acid hydrophilic monomer, resulting in an increase of the friction coefficient. However, the plasticizing effect of a coalescing agent $\left(\right.$ Texanol $\left.^{\mathrm{TM}}\right)$ was much stronger and therefore much more increased the friction coefficient, which only slowly decreased upon film aging. The film containing $10 \%$ of Texanol was used as the reference system for the remainder of the study. To this reference, different classical formulation ingredients were successively added (reference plus ethanol, reference plus thickener, plus crosslinker, plus pigment). Curiously, the presence of ethanol in the aqueous phase, often added in order to speed up evaporation, had an increasing effect, although slight, on the friction coefficient of the dry film. The opposite was observed with the thickener, result interpreted in terms of a marked lubrication phenomenon. Crosslinking or pigment addition significantly decreased the friction coefficient. A positive correlation between friction and film softness could be observed (increase of $\mu$ when film softness increased and inversely), except when lubrication was dominating. These results should be helpful to formulators of waterborne films in several application areas.
\end{abstract}

Keywords:

Waterborne coating; Latex film; Friction; Tribology; Formulation; Plasticization

*yves.holl@unistra.fr 


\section{Introduction}

Friction belongs to the general field of "surface mechanical properties", together with scratch and wear resistance, hardness, adhesion, and more general properties like elastic (Young) modulus and yield stress when they significantly differ from the bulk values [1]. All these properties are interdependent. Studying friction, through measurements of friction coefficients versus various relevant parameters (temperature, sliding velocity, strain rate, normal force, normal pressure, confinement), is important and interesting for two main reasons: (i) it is directly correlated to scratch and wear and (ii) it is highly sensitive to subtle changes in surface (and subsurface) nature, composition, structure and topography. Friction properties of polymers have been extensively studied over the years. Several general books exist on the topic, including recent ones like references 2 and 3 or more classical ones like reference 4 . If we restrict our interest to polymer thin films or organic coatings, literature is still quite abundant, see for instance reference 5 for a general reading.

Friction has two major interdependent components: (i) one arising from the tip (or indenter) / surface adhesion, and (ii) one due to the dynamic strain of the sample under the effect of the moving tip applying a normal stress to the surface. Some authors speak of a "ploughing effect", creating a bulge in front of the indenter (behaving like an advancing boat pushing water apart), to describe the strain experienced by the sample surface during a friction test [6]. Increasing attractive interactions increases energy dissipated by friction and friction coefficient. A ductile material, prone to plastic deformation, submitted to an important normal load at high strain rate will present a higher friction coefficient than a hard, elastic, gently solicited one. It is not straightforward to decouple the contributions to friction of adhesion and of the strain of the material. However, it is generally considered that the adhesion term (the sole extreme surface interactions) in spite of its fundamental importance, has a little quantitative contribution to the global friction energy and, consequently, to the friction coefficient [7], except sometimes with elastomers or at very low pressure.

Another important general consideration is that supported thin films do not behave like the corresponding bulk material when solicited under a sliding tip because of the phenomenon of confinement [8]. When the stress field due to the normal load exerted by the tip interferes with the substrate, the mechanical behavior of the film is altered. For instance, when the substrate is more rigid than the film, above a certain load threshold, the apparent elastic modulus of the film is increased [9] and plastic deformation may appear sooner.

The friction coefficient, ratio of the measured tangential force over the applied normal load, is generally called the "apparent friction coefficient" $\left(\mu_{\text {app }}\right)$. In an attempt to gain more precise insight into the friction process, a model was developed by Lafaye et al. [6] to accede to a more local physical parameter, $\mu_{l o c}$, defined as the ratio of the local shear stress over the local contact pressure. This sophisticated approach was outside the scope of the present work where only apparent friction coefficients will be presented and commented. However, in order to interpret friction results, global mechanical characteristics (Young modulus, yield stress, dynamic conservation modulus) of the whole film were measured and systematically presented after the friction results.

Our main interest is in "latex films", formation mechanisms and structure-property relationships. Latexes (or polymer colloids) form polymeric films upon drying provided particles are soft enough to lose their spherical shape in ambient conditions. Mechanisms of latex film formation in relation to film properties have been extensively studied in the past, over several 
decades. Two major contributors to the field have written a remarkable book summarizing 50 years of research in academia and industry [10]. It is probably known by all readers that the three main steps in latex film formation are drying [11], particle deformation [12] and coalescence [13]. After a peak in publication number in the mid nineteens, the topic is nowadays less "hot". Currently, most of the latest published papers deal with drying in relation to particle deformation [14].

As far as applications and properties are concerned, waterborne systems have been used a long time ago in numerous fields like paints [15, 16], coatings [17], inks [18], adhesives [19], drug delivery [20], and others. Specificities of latex film properties arise from the fact that they keep, to a certain extent, the memory of the particles they were formed from. It means that they can retain traces of antiparticle interfaces and are generally biphasic, one phase being more hydrophilic, the other one more hydrophobic. This latter aspect is a direct consequence of the coreshell structure of the particles. Which phase is continuous depends on the film formation conditions [10]. Another specificity is the presence, in many cases, of a surfactant, necessary in the latex synthesis and/or post-added to improve stability of complex, formulated systems and to allow wetting of some substrates. As expected, surfactants decrease the friction coefficient by a lubricating effect [21].

Several articles specifically devoted to friction properties of latex films can be found in the literature. Most of them are application oriented, with the aim of sometimes increasing [22] but more often decreasing the friction coefficient [23], to quote a few examples. More fundamental contributions are scarcer $[21,24]$. The complexity of the phenomena involved and the diversity of systems under investigation make it difficult to draw general conclusions on the role of different parameters on friction properties.

In practical applications, latex films are never used alone (except perhaps as some special adhesives), they are part of a more or less complex formulation where they most often essentially play the role of a binder. Our aim in this work was to investigate friction properties of waterborne formulations based on latexes. However, as a starting case, the unformulated, pure latex film was studied first, especially with respect to the influence of humidity. In order to avoid the overwhelming lubricating effect of surfactants, the latexes were cleaned by dialysis to get rid of the surfactant used in the synthesis (and all other low molecular weight species like salts, soluble oligomers likely to migrate to the surface and distort the friction measurements). To this starting latex, classical formulation additives were successively added and corresponding friction and mechanical properties measured. The first additive was a plasticizer of the polymer. The plasticized latex became the reference system for the rest of the study. This reference system was then complemented by a co-solvent (ethanol, often used to speed up latex drying), or by a thickener (sodium salt of polyacrylic acid), or by a crosslinker (carbodiimide), or, finally, by a pigment also playing the role of a filler (titanium oxide). Combinations of formulation ingredients were not studied (for example filler in a crosslinked film) but results presented below should enable one to infer properties of more complex blends, at least qualitatively. 


\section{Materials and Methods}

\subsection{Materials}

The starting, unformulated film, was issued from a core-shell acrylic latex synthesized in our laboratory. The particles are composed of random copolymers of n-butyl acrylate $(\mathrm{BuA})$, methylmethacrylate (MMA) and acrylic acid (AA). The monomer ratio was chosen to reach a glass transition temperature $(\mathrm{Tg})$ of the polymer around $45^{\circ} \mathrm{C}$. The percentage of AA, mainly located in the shell of the particles [25], was taken equal to $1 \mathrm{wt} \%$. The mean particle diameter was adjusted to $200 \mathrm{~nm}$. This latex will be denoted "200-1" in the rest of the paper. The monomers, butyl acrylate (Sigma-Aldrich, purity $\geq 99 \%$ ), methyl methacrylate (Merck), acrylic acid (Merck), the surfactant, sodium dodecyl sulfate (SDS, A.C.S Reagent, Sigma Aldrich, purity $>99 \%$ ) and the initiator, sodium persulfate $\left(\mathrm{Na}_{2} \mathrm{~S}_{2} \mathrm{O}_{8}\right.$, reagent grade, Sigma Aldrich, purity $\left.\geq 98 \%\right)$ were used as received. Distilled water was used throughout synthesis and dialysis. The latex synthesis was performed by semi continuous emulsion polymerization, in a double-wall glass reactor under argon atmosphere. The conversion was above $95 \%$. More details about the synthesis can be found in reference 26. After synthesis, the latex was purified by dialysis using a Millipore membrane until the conductivity of water in contact with the latex was less than $3 \mu \mathrm{S} / \mathrm{cm}$. Purification allows elimination of water soluble impurities (residual salts, oligomers and surfactants). After dialysis, the solids content of the latex was adjusted to around $26 \%$ and the $\mathrm{pH}$ to 10.0 by dropwise addition of a $\mathrm{NaOH}$ solution. The latex remained stable after purification thanks to the high concentration of acrylic acid in the shell and high $\mathrm{pH}$ [25]. The main characteristics of the latex 200-1 are summarized in Table 1.

\section{Table 1}

Main characteristics of the latex 200-1 synthesized for this study

\begin{tabular}{|c|c|c|c|c|c|c|c|}
\hline Latex & $\begin{array}{c}\text { Composition } \\
\text { (\%BuA/\%MMA/\%AA) }\end{array}$ & $\begin{array}{l}\text { Mean } \\
\text { particle } \\
\text { diameter }\end{array}$ & $\begin{array}{c}\begin{array}{c}\text { Solids } \\
\text { content }\end{array} \\
( \pm 0.5 \%)\end{array}$ & $\begin{array}{c}\mathrm{Tg} \\
\text { film/dispersion } \\
\left( \pm 1^{\circ} \mathrm{C}\right)\end{array}$ & $\begin{array}{c}\text { Zeta } \\
\text { Potential } \\
* \\
( \pm 1 \mathrm{mV})\end{array}$ & $\begin{array}{c}\text { Measured } \\
\text { Viscosity } \\
* * \\
\text { ( } \pm 0.5 \mathrm{mPa} . \mathrm{s})\end{array}$ & $\begin{array}{c}\text { Calculated } \\
\text { Viscosity } \\
* * *\end{array}$ \\
\hline $200-1$ & $33.3 / 65.7 / 1.0$ & $206 \mathrm{~nm}$ & $25.8 \%$ & $44^{\circ} \mathrm{C} / 31^{\circ} \mathrm{C}$ & $-54 \mathrm{mV}$ & $2.5 \mathrm{mPa} . \mathrm{s}$ & $2.9 \mathrm{mPa} . \mathrm{s}$ \\
\hline
\end{tabular}

\section{Formulation}

Formulation additives were added sequentially (coalescing aid - co solvent - thickener/dispersing agent - crosslinker - pigment/filler), at different amounts, to the latex 200-1. The resulting dispersions were allowed to equilibrate overnight at room temperature under stirring before use.

As plasticizer (or coalescing agent), the well-known Texanol ${ }^{\mathrm{TM}}$ (2,2,4-trimethyl-1,3pentanediol monoisobutyrate) (denoted Tex in the remainder of the paper) was used. It was purchased from Eastman (purity $98.5 \mathrm{wt} \% \mathrm{~min}$ ) and used as received. Latex samples containing 6, 8, 10 and $33 \mathrm{wt} \%$ Tex based upon the solids content were prepared. The film $200-1+10 \%$ Tex 
was taken as reference because it corresponds to a classical amount of Texanol added in paint formulations. The main characteristics of the latex 200-1 with Tex can be found in Table 2 .

Table 2

Main characteristics of the latexes containing Texanol ${ }^{\mathrm{TM}}$

\begin{tabular}{ccccc}
\hline Dispersion & $200-1$ & $+6 \% \mathrm{Tex}$ & $+10 \% \mathrm{Tex}$ & $+33 \%$ Tex \\
\hline Initial quantity of Tex compared to & $/$ & $6.0 \% / 2.0 \%$ & $10.0 \% / 3.3 \%$ & $33.0 \% / 10.0 \%$ \\
solids content /volatile content & & & & \\
Tg of the dispersion $\left( \pm 1^{\circ} \mathrm{C}\right)$ & $31^{\circ} \mathrm{C}$ & $15^{\circ} \mathrm{C} / 46^{\circ} \mathrm{C}$ & $14^{\circ} \mathrm{C} / 45^{\circ} \mathrm{C}$ & Non measurable \\
Tg of the dried dispersion $\left( \pm 1^{\circ} \mathrm{C}\right)$ & $44^{\circ} \mathrm{C}$ & $23^{\circ} \mathrm{C}$ & $18^{\circ} \mathrm{C}$ & Below $-10^{\circ} \mathrm{C}$ \\
Plasticized Polymer $\mathrm{Tg}^{*}$ & $/$ & $28^{\circ} \mathrm{C}$ & $17^{\circ} \mathrm{C}$ & $-26^{\circ} \mathrm{C}$ \\
MFFT $^{*}$ & $30^{\circ} \mathrm{C}$ & $14^{\circ} \mathrm{C}$ & $3^{\circ} \mathrm{C}$ & $-40^{\circ} \mathrm{C}$
\end{tabular}

* Minimum Film Formation Temperature. Calculation based on the Kelley-Bueche equation [27].

The latex $200-1+8 \%$ Tex was not studied in details. It is supposed to have intermediate characteristics between $200-1+6 \%$ Tex and 200-1+10\%Tex.

Absolute ethanol (purity $\geq 99.8 \%$, Sigma Aldrich) ("EtOH") was used as co-solvent and added to the plasticized latex 200-1+10\%Tex. Samples containing 5, 10 and $25 \mathrm{wt} \% \mathrm{EtOH}$, based upon the latex solids content were prepared.

A polyacrylic acid sodium salt ("NaPAA") (Sigma Aldrich, average Mw 15,000, $35 \mathrm{wt} \%$ in $\mathrm{H}_{2} \mathrm{O}$, used as received) was chosen as thickener and dispersing agent for the pigment. Latexes containing $10 \mathrm{wt} \%$ Tex were mixed with a solution of poly(acrylic acid, sodium salt) in such a way that the concentrations of NaPAA in the different samples were: $0.5,1$ and $1.5 \mathrm{wt} \%$ based upon the latex solids content.

Water soluble polycarbodiimides provided by Picassian (XL 702, $40 \mathrm{wt} \%$ in water, used as received) were added to the latex $200-1+10 \%$ Tex in order to crosslink the system. Polycarbodiimides are $\mathrm{pH}$ sensitive, they hydrolyze at $\mathrm{pH}$ lower than 11.0 and their reactivity is highest at $\mathrm{pH} 3.5$ - 4.5 [28]. Prior to the addition of Texanol and XL702, the $\mathrm{pH}$ of the latex 2001 was first adjusted to 4.0 by dropwise addition of hydrochloric acid and then to 11.0 by dropwise addition of an ammonia solution. During drying, the volatile ammonia evaporated and the $\mathrm{pH}$ decreased which favored the reaction between carboxylate groups of the latex and carbodiimide functions. The amounts of polycarbodiimide added to the plasticized latex were: 1,2 and $3 \mathrm{wt} \%$ based upon the latex solids content

As pigment (or filler), titanium oxide provided by Huntsman was used as received (Tioxide ${ }^{\circledR}$ R-TC90, $94 \% \mathrm{TiO}_{2}$, aluminum oxide treatment, crystal size $240 \mathrm{~nm}$ ). It was added to the plasticized latex $200-1+10 \%$ Tex with $0.5 \mathrm{wt} \%$ of NaPAA in water in order to disperse and stabilize the pigment. Stable dispersions were obtained by using the mixing device Ultra-Turrax ${ }^{\circledR}$ IKA T10, with different amounts of Tioxide: 55, 100 and $300 \mathrm{wt} \%$ (based upon the latex solids content). Prior to the dispersion, the latex was diluted in order to reach the same final solids content in all samples.

The characteristics of the formulations can be found in Table 3 . 
Table 3

Main characteristics of the plasticized latexes 200-1+10\%Tex with NaPAA and Tioxide R-TC90

\begin{tabular}{|c|c|c|c|c|}
\hline Formulation & $\begin{array}{c}200-1 \\
+10 \% \text { Tex }\end{array}$ & $\begin{array}{r}+0.5 \% \\
\text { NaPAA }\end{array}$ & $\begin{array}{c}+1 \% \\
\text { NAPAA }\end{array}$ & $\begin{array}{c}+1.5 \% \\
\text { NAPAA }\end{array}$ \\
\hline Solids content $\pm \mathbf{0 . 5 \%}$ & $25.2 \%$ & $25.4 \%$ & $25.7 \%$ & $25.9 \%$ \\
\hline $\begin{array}{l}\% \text { NaPAA in the } \\
\text { aqueous phase }\end{array}$ & $0 \%$ & $0.2 \%$ & $0.4 \%$ & $0.6 \%$ \\
\hline $\begin{array}{c}\text { Size and size } \\
\text { distribution of particle }\end{array}$ & \multicolumn{4}{|c|}{ No significant changes after addition of NaPAA } \\
\hline pH & 10.0 & 9.8 & 9.0 & 8.5 \\
\hline Formulation & $\begin{array}{c}200-1 \\
+10 \% \text { Tex } \\
\end{array}$ & $\begin{array}{c}+55 \% \\
\text { Tioxide } \\
\end{array}$ & $\begin{array}{l}+100 \% \\
\text { Tioxide }\end{array}$ & $\begin{array}{l}+300 \% \\
\text { Tioxide } \\
\end{array}$ \\
\hline Solids content $\pm \mathbf{0 . 5} \%$ & $22.4 \%$ & $23 \%$ & $23 \%$ & $22 \%$ \\
\hline PVC * & / & $14 \%$ & $23 \%$ & $47 \%$ \\
\hline \%NaPAA / water & $0.5 \%$ & $0.5 \%$ & $0.5 \%$ & $0.5 \%$ \\
\hline \%NaPAA / pigments & / & $14 \%$ & $10 \%$ & $7 \%$ \\
\hline Mean particle size (nm) & 220 & 340 & 400 & 400 \\
\hline
\end{tabular}

* Pigment Volume Concentration

The different formulations are summarized as follows:

$-200-1+$ Texanol $(6,8,10$ and $33 \mathrm{wt} \%)$

$-200-1+10 \% \mathrm{Tex}+\operatorname{EtOH}(5,10$ and $25 \mathrm{wt} \%)$

$-200-1+10 \%$ Tex+NaPAA $(0.5,1$ and $1.5 \mathrm{wt} \%)$

$-200-1+10 \% \mathrm{Tex}+\mathrm{XL} 702(1,2$ and $3 \mathrm{wt} \%)$ (XL stands for crosslinker)

$-200-1+10 \%$ Tex + NaPAA $(0.5 \mathrm{wt} \%)+$ Tioxide $(55,100$ and $300 \mathrm{wt} \%)$

\subsection{Methods}

\section{Film formation}

Films were prepared on rectangular, ordinary glass, microscope slides $(76 \times 26 \mathrm{~mm})$ cleaned overnight in a $\mathrm{H}_{2} \mathrm{SO}_{4}$ bath, rinsed in water and then in ethanol. A thin layer of polytetrafluoroethylene (PTFE) (Sprayflon ${ }^{\circledR}$, Roth) was sprayed around the edges of the slides over a width of $3 \mathrm{~mm}$ creating a non wettable rim that confined the latex on a constant area in the central part of the rectangle. A constant volume $(1 \mathrm{~mL})$ of latex was deposited on the PTFE free part of the slide, ensuring the same film thickness for all samples. Drying took place under controlled conditions in a Plexiglas box: $23 \pm 2{ }^{\circ} \mathrm{C}, 75 \pm 2 \% \mathrm{RH}$, still air. After drying the films were stored in the same controlled conditions.

Because of its Tg well above room temperature, the sample 200-1 (without Tex) could not form a crack free film just by drying at room temperature. Therefore, the corresponding films were prepared by pressing the dry powder at $100^{\circ} \mathrm{C}$ and 100 bars for one hour.

The film mechanical properties were tested after drying (and sometimes during aging). The mechanical measurements were performed directly on the dry films (with the exception of the 2001 film as stated above). 


\section{Friction measurements}

Friction measurements were performed on the glass supported films in a home-made tribometer described in details in reference 29. The samples were mounted into a transparent environmental chamber allowing a temperature and relative humidity control. Measurements were performed at $23^{\circ} \mathrm{C}\left( \pm 2^{\circ} \mathrm{C}\right)$, at a fixed velocity of $0.3 \mathrm{~mm} / \mathrm{s}$, at $10,20,45,60$ and $75 \% \mathrm{RH}$ for the $200-1$ film and at $75 \% \mathrm{RH}$ for the other formulated films. The $200-1$ films were allowed to equilibrate overnight at the test relative humidity.

In our tribometer, the sample was moving whereas a fixed indenter was applied on the surface. A built-in microscope allowed an in-situ observation of the indenter/film contact zone and the groove left on the surface through transparent samples. For opaque samples, the contact could be seen through the indenter, provided a transparent one was used. As will be seen below, the shape and size of the contact zone is a crucial piece of information, lacking in most of the tribometers used so far. Three different indenters from Edmund Optics were used in this work: a borosilicate glass sphere (reference BK7) of radius $500 \mu \mathrm{m}$, and sapphire spheres of radii $2 \mathrm{~mm}$ and $4.66 \mathrm{~mm}$. The average roughness of the indenters was low enough to neglect local plasticity under micro-roughness peaks [30]. They were washed in ethanol and dried under nitrogen flow before measurements.

In a standard experiment, the normal load applied by the indenter increased by linearly distributed steps. Our normal load range was 1 to $9 \mathrm{~N}$ (except otherwise stated). At each normal load step, the indenter moved over a distance of a least $2 \mathrm{~mm}$ in order to stabilize the contact area. For a given sample, the shape and size of the contact zone depended on the normal load as well as on the relative humidity. We had access to:

- the apparent friction coefficient $\mu_{a p p}$ which is the ratio of the measured tangential force $F_{T}$ over the applied normal load $F_{N}: \mu_{a p p}=\frac{F_{T}}{F_{N}}$

- the mean contact pressure $p_{m}$ which is equal to the normal load $F_{N}$ divided by the contact area $A_{c}: p_{m}=\frac{F_{N}}{A_{c}}$

- the rear contact angle $\omega$ defined by Lafaye et al. in their model [6]. This angle is a way to characterize the shape of the film/indenter contact zone (see Fig. 1). It depends on the behavior of the material under sliding normal load. It varies from $90^{\circ}$ for an elastic contact to almost zero for a fully plastic contact, the intermediate values corresponding to viscoelastic or elastoplastic contacts.

- the film confinement defined as the indentation depth $\mathrm{h}$ over the film thickness $\mathrm{t}$. The indentation depth $\mathrm{h}$ is determined knowing the indenter radius $R$ and the contact area radius $r_{c}: \mathrm{h}=R-\sqrt{R^{2}-r_{c}^{2}}$

When the substrate is more rigid than the film $\left(E_{\text {support }}>E_{\text {film }}\right.$ with $E$ the Young modulus), the real strain experienced by the polymeric film is higher than for a semi-infinite system because the film is confined between two rigid surfaces: the indenter and the substrate. In this case the strain is higher than the mean strain calculated for an Hertzien contact and early plasticity can occur in the film. When the substrate is less rigid than the film $\left(E_{\text {support }}<E_{\text {film }}\right)$, the stress can elastically propagate inside the film toward the substrate. The substrate, being softer and with an elastic limit 
lower than the film, can plastically deform. Our systems are clearly in the first situation. That is the reason why it is often relevant to express surface mechanical characteristics like friction coefficients or contact pressures versus confinement, as will be seen in the results below.
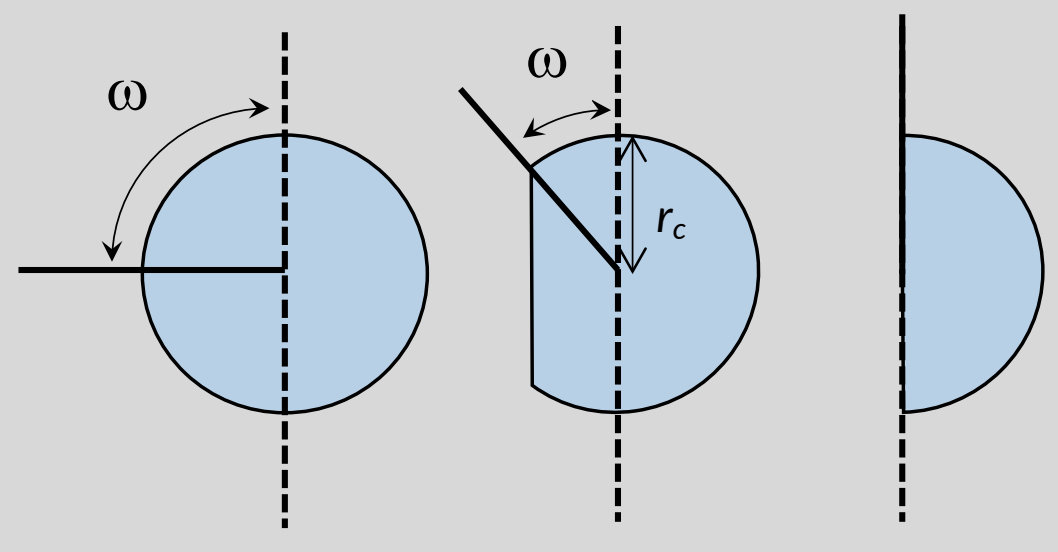

$$
\omega=90^{\circ}
$$

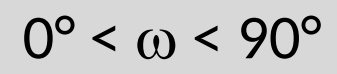

$\omega=0^{\circ}$

Fig. 1. Various possible shapes of the contact zone between the film and a spherical indenter, characterized by the rear contact angle $\omega$. The indenter moves to the right. The shape is indicative of the nature of the contact: elastic when it is circular $\left(\omega=90^{\circ}\right)$, plastic when it is almost half circular $\left(\omega \approx 0^{\circ}\right)$, elastoplastic or viscoelastic when it is a truncated circle $\left(0^{\circ}<\omega<90^{\circ}\right)$ (see [6]). Our tribometer allows us to see the contact (and measure its area) either through the sample when it is transparent or through a transparent indenter when the sample is opaque.

Friction tests must be performed on films with the same thickness in order to provide comparable confinement situations. However, latex films are usually thicker near the edge. A tactile rugosimeter (Akilog®) was used to localize the planar areas of thickness $200 \pm 20 \mu \mathrm{m}$ and friction measurements were made on those areas which are parallel to the longer side of the films. Each film was tested at least three times and the average and standard deviation of $\mu_{a p p}, p_{m}, \omega$ were taken as results. Even so, the precision of the measurements, expressed as the standard deviation over the average value in percent, is in the range $15-20 \%$ or more. This is an usual situation in most of mechanical measurements.

\section{Viscoelastic properties}

In order to help interpreting friction measurements, the viscoelastic properties of the dry films were measured by dynamic mechanical analysis (DMA) using a homemade piezoelectric rheometer described in details elsewhere [31]. This device, called piezorheometer, is a plate-plate rheometer operating with piezoelectric ceramics vibrating in shear mode at very low strain (around $10^{-5}$ ), ensuring measurements in the linear regime. The real and imaginary parts of the complex shear modulus were measured at different temperatures, at frequencies ranging from $0.2 \mathrm{~Hz}$ to $1000 \mathrm{~Hz}$. 
Tensile tests

In order to accede to the Young modulus and the yield stress (or elastic limit) of the various films, large strain tensile tests were performed with an Instron E3000 machine, equipped with a $100 \mathrm{~N}$ load cell. Measurements were made on free standing samples peeled off their glass substrate, at room temperature, at a strain rate of $0.025 \mathrm{~s}^{-1}$, corresponding to a strain increasing from 0 to 150 $\%$ in 60 seconds. Before measurements, all films were conditioned at $23^{\circ} \mathrm{C}$ and $75 \% \mathrm{RH}$. 


\section{Results and Discussion}

\subsection{Starting unformulated film (200-1). Hydroplasticization}

Fig. 2 presents the friction coefficient $\mu_{a p p}$ versus normal load of films conditioned at different relative humidity. Friction coefficients are comprised between 0.1 and slightly less than 0.4 , classical values for glass (BK7) on polymers below Tg. They show a tendency to increase with both normal load (as classically expected [29]) and relative humidity. Thanks to the observation of the shape of the contact zone (see Fig.2 images a, b, c, d, e), transitions can be identified upon normal load increase: i) an elastic/elastoplastic transition (green line in Fig. 2) and ii) elastoplastic/"plastic like" transitions (red lines). The expression "plastic like" is used here because we cannot assert that the transition is purely plastic. Indubitably, the contact is highly dissymmetric. However, if the transition was purely plastic, a clear permanent groove should appear behind the contact, which is not always the case. Instead, we are in presence of a complex transition mixing viscoelasticity and partial plasticity. At this stage, it is not possible to be more precise.
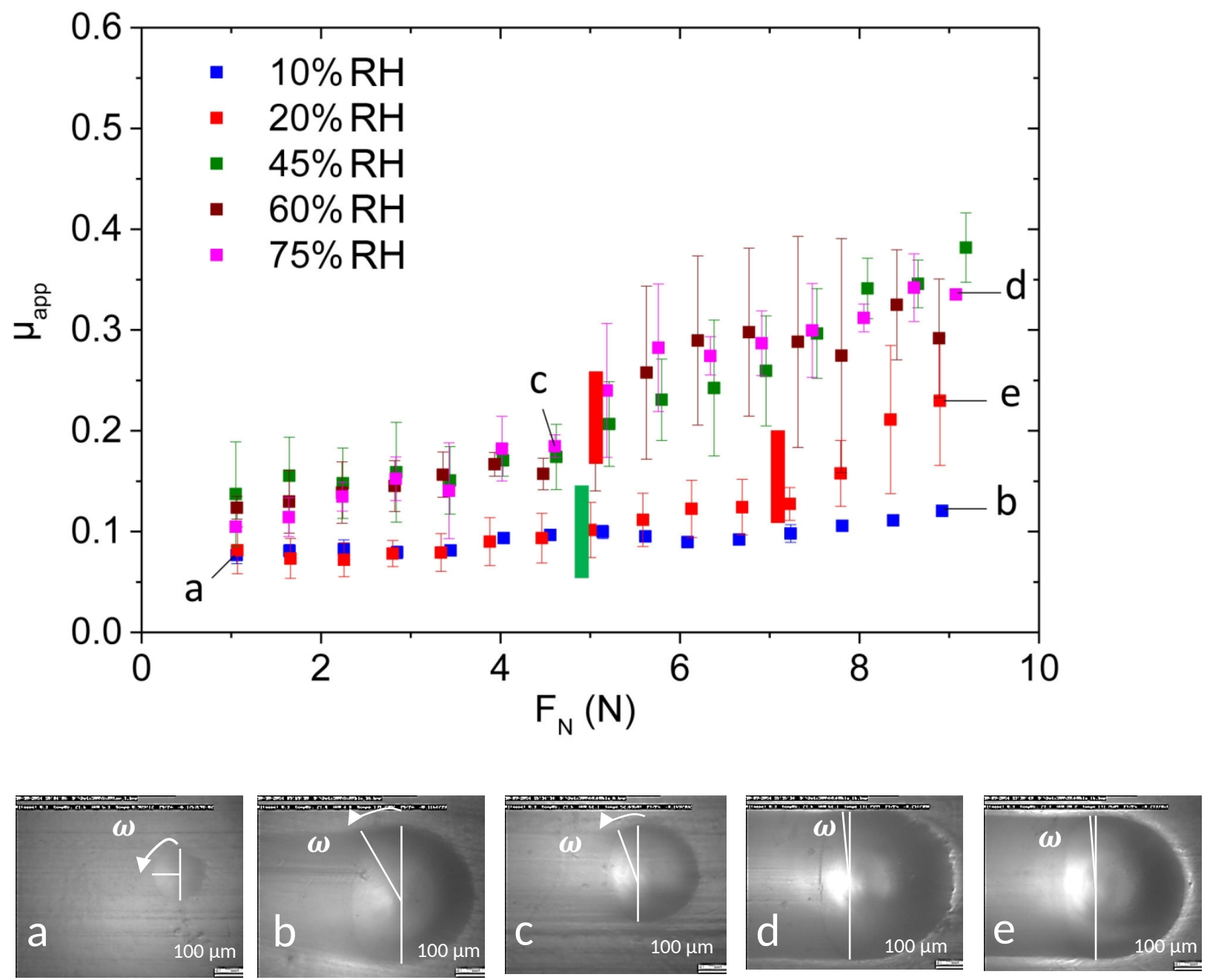

Fig. 2. Friction coefficient $\mu_{\text {app }}$ as a function of normal load $F_{N}$ for the 200-1 film at different relative humidity (as indicated in the insert). Glass indenter, $R=500 \mu \mathrm{m}$. Images a to e represent 
the contact between the glass indenter and the film. The vertical green and red bars are the elastic/elasto-plastic and the elasto-plastic/plastic like transitions, respectively.

In contact mechanics, it is more relevant to represent friction coefficients versus contact pressure than versus normal load. This is shown in Fig. 3, split in two parts for clarity. $\mu_{a p p}$ increases with contact pressure and relative humidity. The two transitions elastic/elastoplastic and elastoplastic/plastic like are indicated in the figure as T1 and T2, respectively. They clearly appear now as slope changes in the curves. The positions of $\mathrm{T} 1$ and $\mathrm{T} 2$ on the pressure axis $\left(\mathrm{P}_{\mathrm{T} 1}\right.$ and $\left.\mathrm{P}_{\mathrm{T} 2}\right)$ are shifted toward lower values with increasing RH (see Table 4). It has to be noted that the increase of $\mu_{a p p}$ with $\mathrm{RH}$ levels off at high $\mathrm{RH}$ : within experimental errors, friction coefficients are identical for $60 \% \mathrm{RH}$ and $75 \% \mathrm{RH}$.

(a)

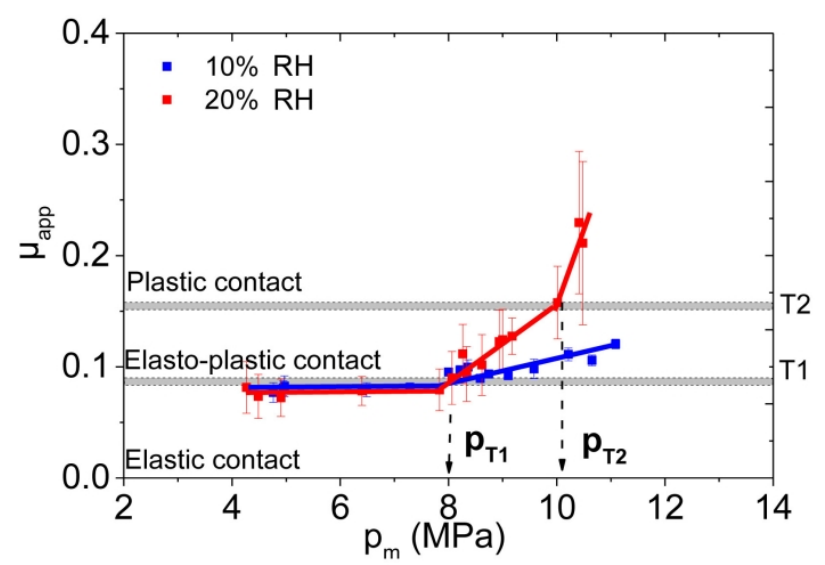

(b)

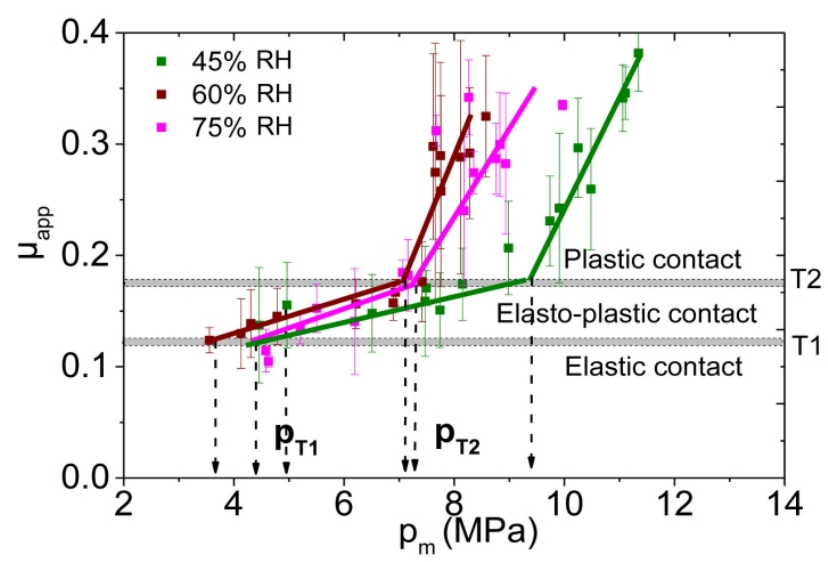

Fig. 3. Friction coefficient $\mu_{\text {app }}$ as a function of average normal pressure $p_{m}$ for the 200-1 film at different relative humidity. Glass indenter, $R=$ $500 \mu \mathrm{m}$. Transitions $\mathrm{T} 1$ and $\mathrm{T} 2$ and corresponding normal pressures $\left(\mathrm{P}_{\mathrm{T} 1}\right.$ and $\left.\mathrm{P}_{\mathrm{T} 2}\right)$ as indicated.

\section{Table 4}

Positions of the elastic/elastoplastic (T1) and elastoplastic/plastic like (T2) transitions on the contact pressure axis $\left(\mathrm{P}_{\mathrm{T} 1}\right.$ and $\left.\mathrm{P}_{\mathrm{T} 2}\right)$ and confinement at maximum normal $\operatorname{load}\left(F_{N}=9 \mathrm{~N}\right)$ at different relative humidity.

\begin{tabular}{cccccc}
\hline Relative humidity & $\mathbf{1 0 \%} \mathbf{R H}$ & $\mathbf{2 0 \%} \mathbf{R H}$ & $\mathbf{4 5 \%} \mathbf{R H}$ & $\mathbf{6 0 \%} \mathbf{R H}$ & $\mathbf{7 5 \%} \mathbf{R H}$ \\
\hline $\boldsymbol{P}_{\boldsymbol{T} 1}(\mathrm{MPa})$ & 8.2 & 8.0 & 4.9 & 3.6 & 4.2 \\
$\boldsymbol{P}_{\boldsymbol{T} 2}(\mathrm{MPa})$ & $\square 11.0$ & 10.1 & 9.5 & 7.1 & 7.3 \\
$\left.(\boldsymbol{h} / \boldsymbol{t})\right|_{\boldsymbol{F}_{\boldsymbol{N}}=\mathbf{9 N}} ^{(+/-\mathbf{0 . 1} \%)}$ & $11.3 \%$ & $13.2 \%$ & $15.3 \%$ & $15.8 \%$ & $18.6 \%$ \\
\hline
\end{tabular}

It is rather straightforward to interpret the increase of $\mu_{a p p}$ with relative humidity by a plasticizing effect of the polymer by water. The 200-1 film can be considered as a heterogeneous biphasic system, one phase being a hydrophobic butyl acrylate $(\mathrm{BuA}) /$ methylmethacrylate (MMA) random copolymer, representing by far the largest volume fraction, and one phase 
composed of BuA / MMA / acrylic acid (AA), rich in AA and therefore significantly hydrophilic. Acrylic acid is usually added to the polymeric chain of latex particles in order to improve the stability of the dispersion, to provide reactive groups for cross linking and to enhance film adhesion on various substrates [32]. The morphology of the biphasic film is not known but, having been annealed at $100^{\circ} \mathrm{C}$ for one hour, it is likely that the hydrophilic phase exists as small dispersed domains in a hydrophobic matrix [33]. This hydrophilic part is prone to plasticization by water (hydroplasticization), reducing the glass transition temperature and the rigidity of the film when exposed to increasing amounts of water in ambient air. The film becoming softer, the indenter penetrates more, increasing the apparent friction coefficient. It is also possible that the glass / polymer interactions are increased when water is present in the film [24]. On the other hand, our results indicate that hydroplasticization levels off above $60 \% \mathrm{RH}$, in other words that a saturation of water uptake by the film occurs. The shift of the transitions towards lower contact pressures also confirms the softening of the film when RH increases.

The softening of the film upon exposure to increasing $\mathrm{RH}$ is further confirmed when plotting the contact pressure versus confinement (Fig. 4). Transitions appear at lower confinement when $\mathrm{RH}$ increases. A clear criterion is also that the maximum confinement increases with increasing RH (Table 4).

It is known that, for thin polymeric films between two rigid surfaces, the substrate influences the film mechanical properties when the confinement reaches around $10 \%$ [34]. This position of $10 \%$ is indicated in Fig. $4 \mathrm{a}$ and $\mathrm{b}$ by solid black lines. The dotted lines on both sides of the $10 \%$ line show the domain in which the confinement transition may occur due to variations in the film thickness. There is a correlation between the elastoplastic/plastic like transition and the confinement transition: the influence of the rigid substrate facilitates the appearance of irreversible deformation in the film.

(a)

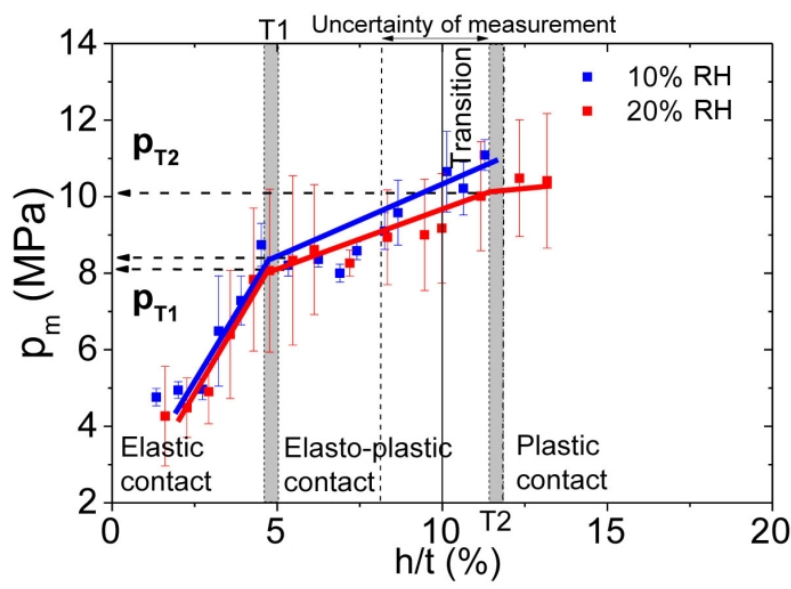

(b)

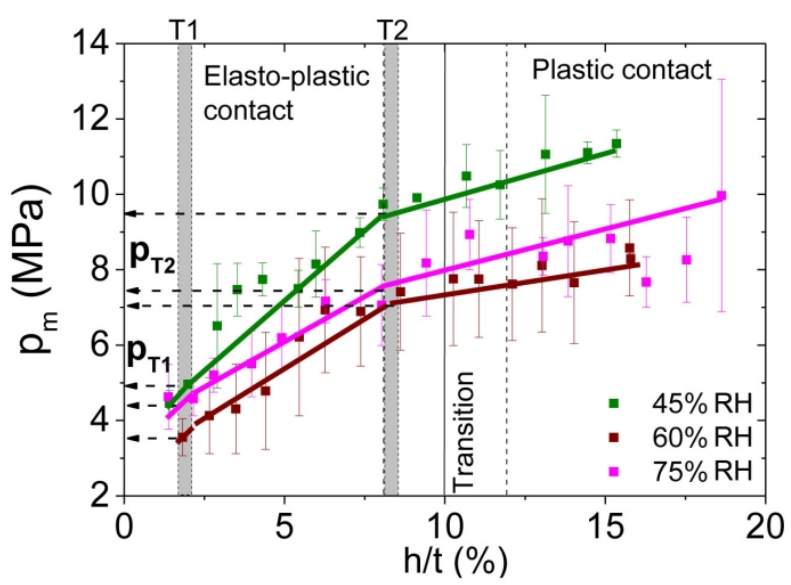

Fig. 4. Contact pressure versus confinement for the 200-1 film at different relative humidity. Glass indenter, $R=500 \mu \mathrm{m}$. Transitions $\mathrm{T} 1$ and $\mathrm{T} 2$ and corresponding normal pressures $\left(\mathrm{P}_{\mathrm{T} 1}\right.$ and $\left.\mathrm{P}_{\mathrm{T} 2}\right)$ as indicated. $10 \%$ confinement is the limit above which the rigid glass substrate influences the results. This limit is actually a domain due to errors in measurements. 


\subsection{Plasticized film}

A plasticizer (solvent of the polymer) is often added to waterborne films as coalescing aid in organic coating applications [35]. It softens the polymer, allowing particle deformation and chain interdiffusion [36] at room temperature. After film formation, the coalescing aid evaporates, restoring the higher glass transition temperature of the unplasticized polymer and, therefore, a more rigid, more scratch resistant, less tacky film. The very classical coalescing agent Texanol ${ }^{\mathrm{TM}}$ (called Tex) was used in our work [37].

Its plasticization role is confirmed in Fig. 5 by the radical change in the rear contact angle $\omega$. In presence of Tex, $\omega$ is close to zero whatever the confinement which indicates plasticized contact. No more elastic/elasto-plastic transition is observed even at low confinement, unlike the Tex free, unplasticized film.

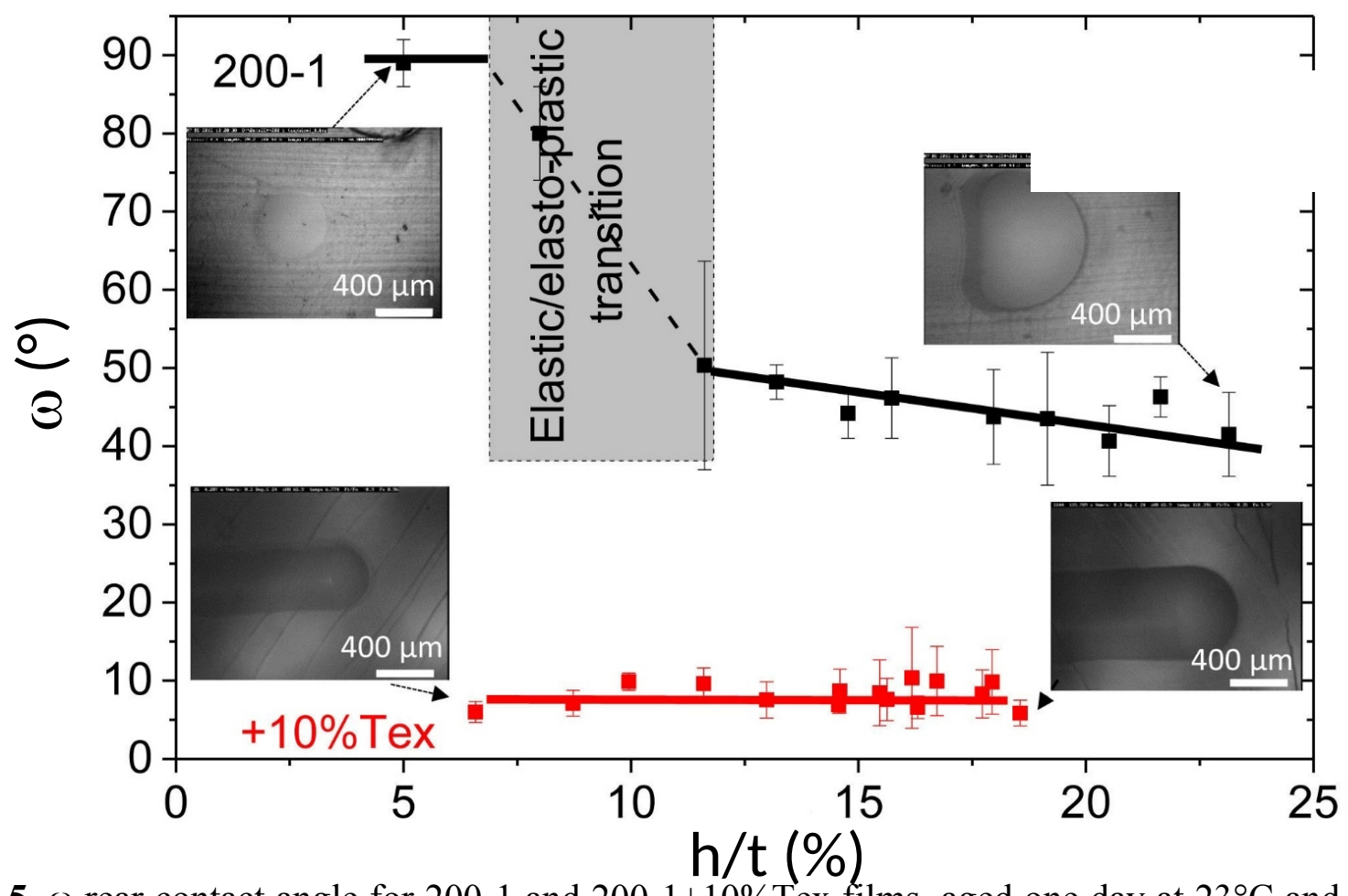

Fig. 5. $\omega$ rear contact angle for $200-1$ and $200-1+10 \%$ Tex films, aged one day at $23^{\circ} \mathrm{C}$ and $75 \%$ RH. The normal load was increased from $1 \mathrm{~N}$ to $9 \mathrm{~N}$ for $200-1$ and from $1 \mathrm{~N}$ to $6 \mathrm{~N}$ for $200-$ $1+10 \%$ Tex. Sapphire indenter, $R=2 \mathrm{~mm}$.

Fig. 6 shows friction coefficients versus confinement for films containing increasing amounts of Tex $(0,6,8$ and $10 \%)$. The film containing $33 \%$ Tex was too soft to be measured, even at low normal load. Like in Fig. 4, the confinement transition clearly appears in the curve shapes around $10 \%$ (the transition zone is rather wide because of the errors on the film thickness measured with the standard contact profilometer). At low confinement, before the transition, where the intrinsic film characteristics are measured, the friction coefficients increase with the Tex content. The Tex free 200-1 film, even plasticized by water, has a much lower friction coefficient $(\sim 0.07$ at $\mathrm{h} / \mathrm{t}=5)$ compared to the Tex containing films $(\sim 0.6$ for $200-1+6 \%$ Tex $)$. Tex, present in the whole film volume and good solvent of the polymer, is obviously more efficient than water 
as a plasticizer. The reasons why plasticized films have high friction coefficients are the same as discussed in the previous section: film softening allowing deeper penetration of the indenter in the film and, possibly, increased indenter/ film attractive interactions. After the confinement transition (above $\mathrm{h} / \mathrm{t}=10 \%$, right side of Fig. 6), no longer the properties of the film itself are measured but that of a film / substrate complex, more and more rigid as confinement increases. Consequently, $\mu_{\text {app }}$ decreases with increasing confinement. Still, despite of the increased rigidity, the contact remains plastic like.

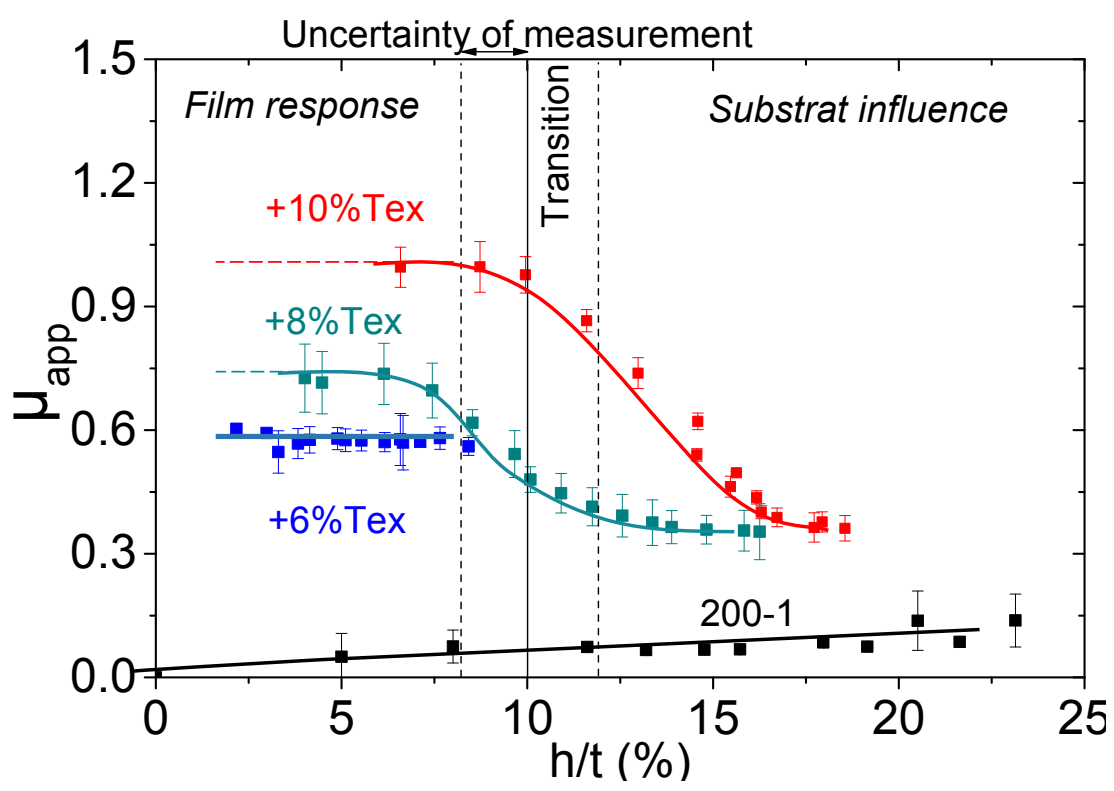

Fig. 6. Friction coefficient $\mu_{\text {app }}$ as a function of confinement $\mathrm{h} / \mathrm{t}(\%)$ for films containing increasing amounts of Tex, aged one day at $23^{\circ} \mathrm{C}$ and $75 \% \mathrm{RH}$. The normal load was increased from $1 \mathrm{~N}$ to $9 \mathrm{~N}$ without Texanol and from $1 \mathrm{~N}$ to $6 \mathrm{~N}$ with Texanol. Sapphire indenter, $2 \mathrm{~mm}$.

Film softening and $\mathrm{Tg}$ shift to lower values upon Tex introduction was confirmed by viscoelastic measurements (Fig. 7). G' vs temperature and phase angle between stress and strain vs temperature are presented in Fig. 7, (a) and (b), respectively. It can be seen that G' decreases indeed and that Tgs are shifted downward upon Tex addition.

(a)



(b)

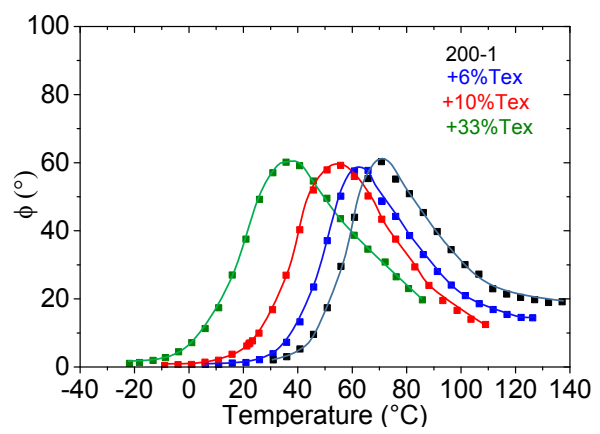

Fig. 7. Viscoelastic properties of the films $200-1$ and t 200-1 plus Texanol (6\%, 10\% and 33\%) measured with a piezoelectric rheometer at $40 \mathrm{~Hz}$. (a) $\mathrm{G}^{\prime} / \rho$ vs T; (b) stress / strain phase shift vs T.

Film aging 
Texanol being supposed to evaporate after film formation in order to restore the properties of the unplasticized polymer, it was interesting to follow the evolution of the film characteristics upon film aging. Because of its very low vapor pressure at room temperature, Tex evaporates quite slowly (much slower than water). The changes of mechanical properties due to the evaporation of Texanol were followed by measuring the friction coefficient vs confinement (Fig. 8.a), the Young modulus $E$, and the elastic limit $\sigma_{y}$ (Fig. 8.b and Table 5) of the film 200-1+10\%Tex upon time at $75 \% \mathrm{RH}$. In the friction coefficient curves, the confinement transition is visible as in Fig. 6 . At the low confinement side, it can be observed that $\mu_{a p p}$ decreases upon film aging, from around 1 to 0.7 after 100 days. This is correlated to an increase of the Young modulus and of the elastic limit of the polymer (Table 5). The Young modulus increases due to the shift of Tg (see Fig. 9). There is less plasticity in the contact, less hindrance to the indenter motion and the friction coefficient goes down. The friction coefficient of the D100 200-1+10\%Tex film at low confinement is identical to the one of the D1 200-1+8\%Tex film in Fig. 6, which tends to indicate that only $20 \%$ of Texanol (Tex concentration goes down from $10 \%$ to $8 \%$ ) evaporated after 100 days at $75 \%$ RH. If this result is linearly extrapolated, the totality of Tex would need at least 500 days to evaporate.

The decrease of the friction coefficient at the high confinement side (Fig. 8) is due to the influence of the substrate, as discussed before. It was checked that the film thickness did not significantly change during aging. Consequently, the shift of the confinement transition toward lower confinement seen in Fig. 8 occurs because of the increase in the film rigidity.

(a)

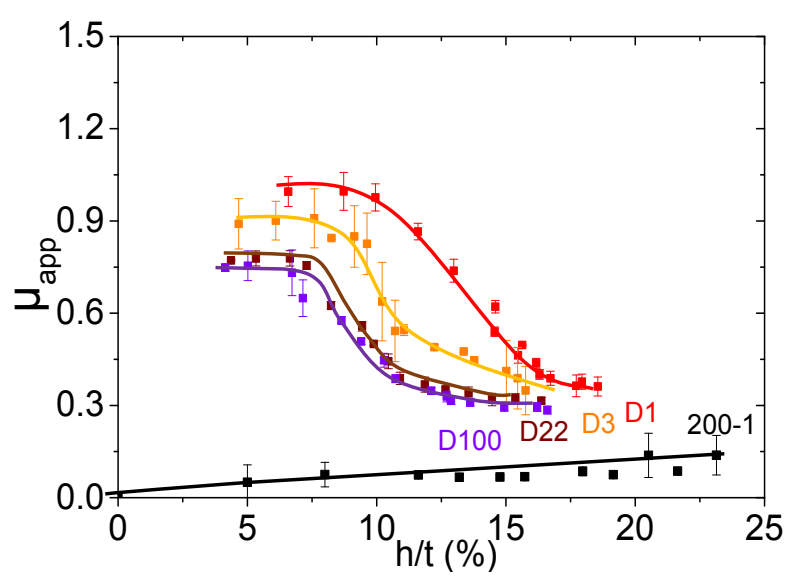

(b)

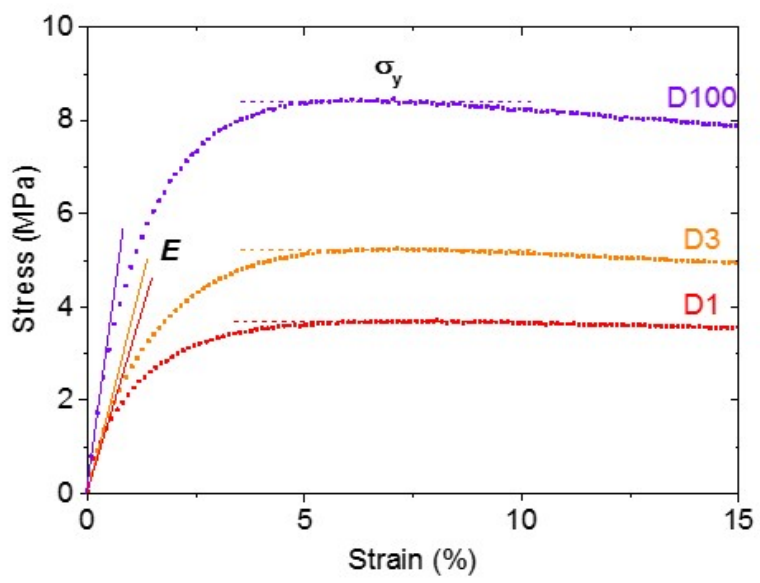

Fig. 8. Evolution of mechanical properties of the film $200-1+10 \%$ Tex during aging. (a) Friction coefficient as a function of the film confinement $\mathrm{h} / \mathrm{t}(\%)$ at different times (one day D1, 3 days D3, 22 days D22 and 100 days D100). Films were stored at $75 \% \mathrm{RH}$ and $23^{\circ} \mathrm{C}$. Sapphire indenter, 2 mm. (b) Stress vs strain curves for the D1, D3 and D100 films. 
Table 5

Young modulus $E$ and elastic limit $\sigma_{\mathrm{y}}$ from curves 8.b

\begin{tabular}{cccc}
\hline $\mathbf{1 0} \%$ Tex & D1 & D3 & D100 \\
\hline $\boldsymbol{E}\left(10^{8} \mathrm{~Pa}\right)(+/-0.3)$ & 2.2 & 3.4 & 6.3 \\
$\boldsymbol{\sigma}_{\boldsymbol{y}}\left(10^{6} \mathrm{~Pa}\right)(+/-0.1)$ & 3.7 & 5.2 & 8.4 \\
\hline
\end{tabular}

Fig. 9 shows the very slow increase of Tg, measured by DSC, of the film 200-1+10\%Tex upon aging. A linear extrapolation of the curve beginning leads to a time around 20,000 years to reach the initial value of the unplasticized polymer $\left(44^{\circ} \mathrm{C}\right)$, in massive disagreement with the previous estimation of 500 days.

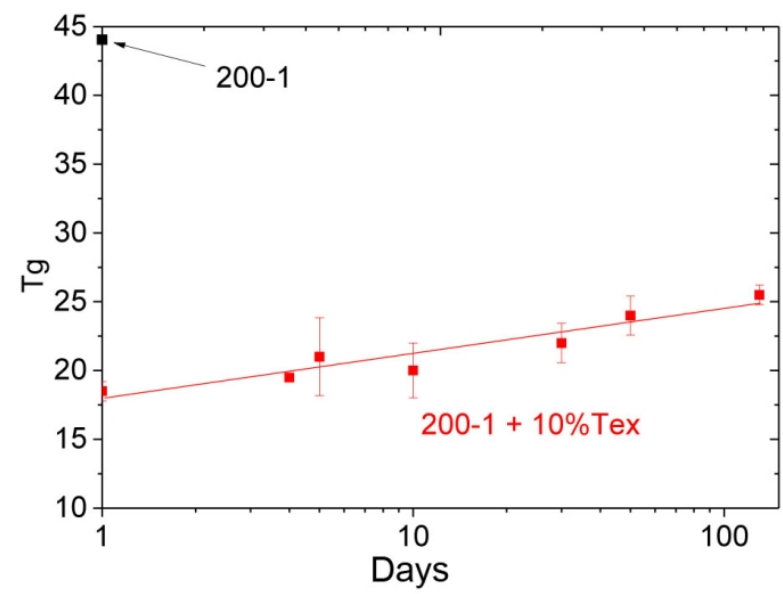

Fig. 9. $\mathrm{Tg}$ of the film $200-1+10 \%$ Tex versus time during aging at $75 \% \mathrm{RH}$ and $23^{\circ} \mathrm{C}$.

It has been known for a long time that solvent evaporation from a polymer solution dramatically slows down when Tg of the solution becomes higher than ambient temperature [38]. When the solvent free polymer has a $\mathrm{Tg}$ higher than room temperature, residual solvent may remain in a solvent based paint for years. To get rid of it, evaporation has to take place at a temperature well above $\mathrm{Tg}$ of the polymer [39]. It was also established that solvent evaporation from the glassy state leads to out of equilibrium chain conformations resulting in residual stress in the film [40]. All this to state that a polymer / Texanol blend left at room temperature will probably never lose the total amount of Tex initially introduced and entirely recover the properties of the pure polymer.

\subsection{Role of ethanol as a co-solvent}

Fast evaporating alcohols are often added in water based formulations in order to speed up elimination of the continuous phase. Ethanol was used in this study. One could expect that, as the whole amount of alcohol is evaporated, the final film would behave like if pure water was used. Fig. 10 shows that this is not exactly the case: the film keeps the memory of the nature of the continuous phase is was issued from, even a rather long time after film formation (30 days in this case). The figure shows that mixing increasing amounts of ethanol with water in the dispersion, shifts the friction coefficient upwards. The effect is not dramatic: from 0.6 for $0 \%$ to 0.9 for $25 \%$ 
ethanol, but still significant and interesting. In this series of experiments, a larger indenter of a different nature was used, so results should not be compared with those in Figs. 6 and 8.



Fig. 10. Friction coefficient as a function of confinement for films $200-1+10 \%$ Tex with different amounts of ethanol, aged 30 days at $75 \% \mathrm{RH}$ and $23^{\circ} \mathrm{C}$. Glass indenter, $R=500 \mu \mathrm{m}$.

Our interpretation of this result is that the particles are swollen by ethanol [41,42] and this swelling enhances the particle plasticization by the coalescing aid [43], leading to a higher friction coefficient. As the 200-1 particle shell is rich in acrylic acid, and ethanol is a good solvent of the poly(acrylic acid) homopolymer, it seems likely that ethanol swells the polymer indeed.

\subsection{After thickening the latex}

Sodium salt of poly(acrylic acid) ("NaPAA") was added to the latex $200-1+10 \%$ Tex as thickener. Fig. 11 presents the friction coefficients versus confinement for films with increasing concentrations of NaPAA. Friction coefficients of NaPAA containing films look similar independently of the thickener amount and much lower than that of the reference film. The only difference is that the maximum confinement increases with the NaPAA concentration, signature of an increasing softness of the films. The confinement transition, clearly visible for 200$1+10 \%$ TEX is no longer observed for the NaPAA containing films. A slight increase of $\mu_{a p p}$ at low confinement might suggest the existence of a transition at very low confinement. However, this would be the case for films with increased rigidity compared to the reference, in contradiction with the previously mentioned observation (increasing maximum confinement) and with the following ones. The $\omega$ angle is lower for the reference indicating that the indenter slides easier when NaPAA is present in the films.

Fig. 12 and Table 6 present the mechanical properties of the film 200-1+10\%Tex without and with NaPAA, measured in a tensile test, and the film Tgs measured by DSC. Young moduli and yield stresses decrease as the concentration of NaPAA increases, whereas no significant effect is detected on Tgs, DSC being not sensitive enough for the low concentration range involved (maximum 1.5\%). 


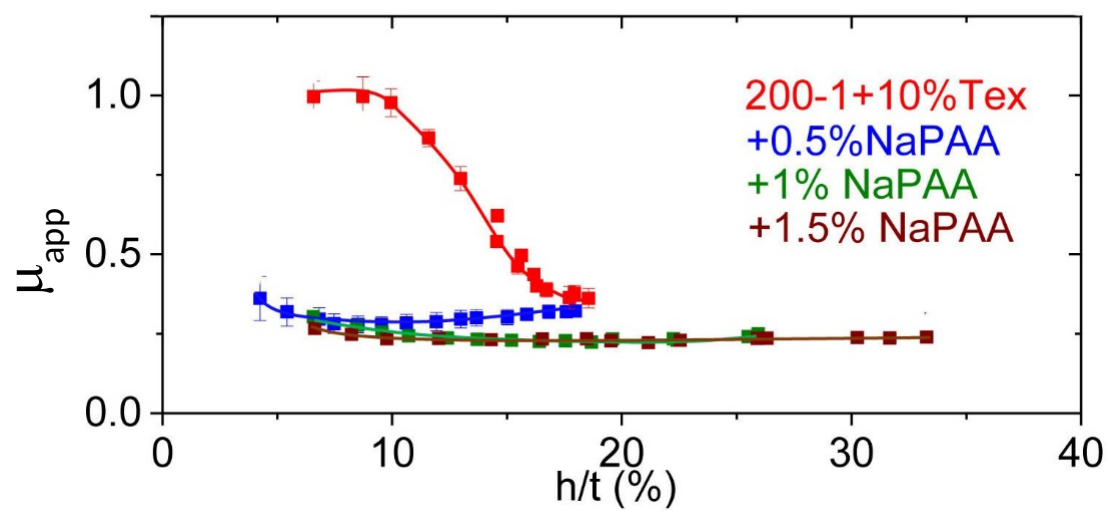

Fig. 11. Friction coefficient $\mu_{\text {app }}$ as a function of confinement for the films $200-1+10 \%$ Tex with NaPAA $(0.5 \%, 1 \%$ and $1.5 \%)$ aged one day at $23^{\circ} \mathrm{C}$ and $75 \% \mathrm{RH}$. The normal load was increased from $1 \mathrm{~N}$ to $6 \mathrm{~N}$. Sapphire indenter, $R=2 \mathrm{~mm}$.



Fig. 12. Stress vs strain curves of the latex films $200-1+10 \%$ Tex plus NaPAA aged one month at $23^{\circ} \mathrm{C}$ and $75 \% \mathrm{RH}$. 


\section{Table 6}

Tg, Young modulus $E$ and elastic limit $\sigma_{\mathrm{y}}$ for the films $200-1+10 \%$ Tex plus NaPAA aged one month at $23^{\circ} \mathrm{C}$ and $75 \% \mathrm{RH}$.

\begin{tabular}{ccccc}
\hline Latex & $\mathbf{1 0 \% T e x}$ & $\begin{array}{c}+\mathbf{0 . 5 \%} \\
\text { NaPAA }\end{array}$ & $\begin{array}{c}+\mathbf{+ 1 \%} \\
\text { NaPAA }\end{array}$ & $\begin{array}{c}+\mathbf{1 . 5 \%} \\
\text { NaPAA }\end{array}$ \\
\hline $\operatorname{Tg}\left(+/-1^{\circ} \mathrm{C}\right)$ & $23^{\circ} \mathrm{C}$ & $24^{\circ} \mathrm{C}$ & $24^{\circ} \mathrm{C}$ & $24^{\circ} \mathrm{C}$ \\
$E\left(10^{8} \mathrm{~Pa}\right)(+/-0.3)$ & 6.8 & 4.7 & 3.1 & 2.6 \\
$\sigma_{y}\left(10^{6} \mathrm{~Pa}\right)(+/-0.1)$ & 8.4 & 7.4 & 4.4 & 3.5 \\
\hline
\end{tabular}

NaPAA is a water soluble polyelectrolyte, it remains in the aqueous phase of the latex. Upon drying, NaPAA will first constitute the continuous phase of the film, together with the hydrophilic acrylic acid rich polymer of the particle shells. This structure with a continuous hydrophilic phase and a dispersed hydrophobic phase made of the particle cores may remain as it is or it may evolve, leading to a more or less complete phase inversion [44]. Knowing the exact structure of the film requires sophisticated experimental technics like small angle neutron scattering [45] which were outside of the scope of this work. However, it will be seen that the preceding results are easier interpreted within the hypothesis of the first structure (continuous hydrophilic phase) which therefore looks more likely.

No doubt that addition of NaPAA softens the films (both $E$ and $\sigma_{y}$ decrease). It was shown in paragraph 3.1. that water from a humid ambient air (75\% RH) plasticized the $200-1$ film. With NaPAA, plasticization by water is most likely even stronger. The same totally dry films would have presented the opposite behavior (increase of $E$ and $\sigma_{y}$ ) because $\mathrm{Tg}$ of polyacrylic acid is above $100^{\circ} \mathrm{C}$ and that of the corresponding sodium salt even higher because of ionic interactions between each repeating units.

It is hard to be affirmative but it seems that the contrast in mechanical properties (Table 6) between the reference film and the ones containing NaPAA would have been less pronounced in case of a reversed structure (hydrophilic phase dispersed in a continuous hydrophobic one), in part because the volume fraction of the hydrophilic phase is very low (in the range of a couple of percent). Models exist that would have helped being more quantitative by enabling one to calculate the global mechanical properties of the blend of the hydrophilic and hydrophobic phases, depending on its structure, and compare to the actual experimental values [46, 47]. However, data are missing (moduli of the pure phases and interfacial tension) to do so. Another argument in favor of NaPAA being in the continuous phase, and therefore at the film surface, comes now, through the analysis of the friction results.

Until now, it was stated that increasing the softness increases the friction coefficient (Fig. 3 \& Fig. 6) because the indenter penetrates more in the film, a resisting bulge is formed ahead of the moving indenter and hence motion is more hindered. The situation is here opposite (Fig. 11). NaPAA at the surface, plasticized by water, is so soft that it does not resist much to the indenter motion. This is typically the case of a lubricated contact $[48,49]$. In the conditions of our experiments, NaPAA acts as a lubricant. 


\subsection{Crosslinked film}

A cross-linker, XL 702 was added to the latex stabilized with ammonia. During the evaporation of ammonia and water, the $\mathrm{pH}$ of the latex decreased and the cross-linking reaction occurred (see materials and methods). Fig. 13 shows the friction coefficients versus confinement for the films with increasing crosslinking ratios. It can be seen that $\mu_{\text {app }}$ decreases upon increasing crosslinking and that the confinement transition is shifted toward lower confinements.

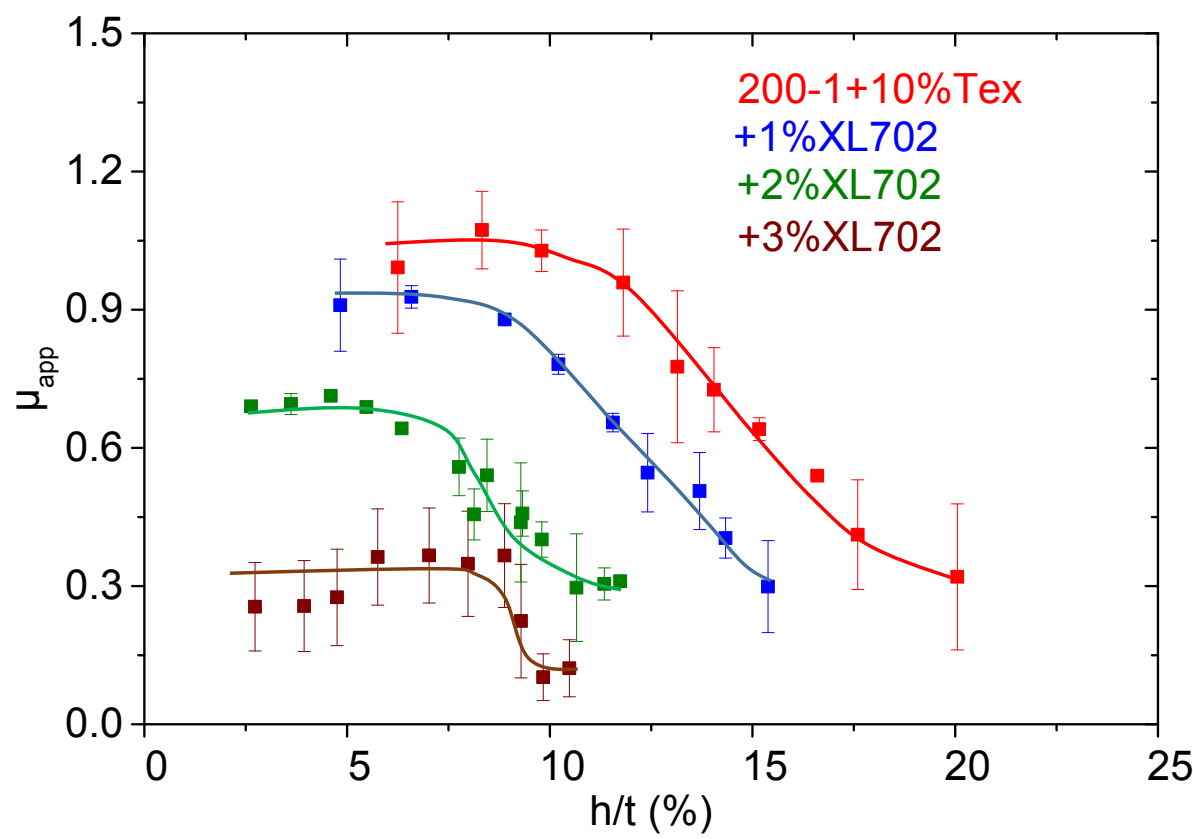

Fig. 13. Friction coefficient $\mu_{\text {app }}$ as a function of the confinement $h / t$ for the films $200-1+10 \%$ Tex crosslinked by increasing amounts of XL702, aged one day at $23^{\circ} \mathrm{C}$ and $75 \% \mathrm{RH}$. Sapphire indenter, $R=2 \mathrm{~mm}$.

Fig. 14 and Table 7 present the mechanical properties of the dried films measured in a tensile test and the film Tgs measured by DSC. One can see that an increase in the percentage of XL 702 results in increased mechanical properties, as expected. However once the value of $2 \%$ is reached, $\operatorname{Tg}$ and $\sigma_{y}$ do not increase further, whereas $E$ continues to increase.

As far as friction is concerned (Fig. 13), results follow the evolution of the Young modulus. This situation was met previously (see Fig. 6 and Fig. 8), an increased film rigidity has the consequence of lowering the friction coefficient and shifting the confinement transition toward lower confinements. The fact that $\sigma_{y}$ levels off at $2 \%$ XL 702 whereas $E$ still increases when XL702 reaches $3 \%$ could be due to a saturation of the crosslink density at $2 \%$ with an excess of solid XL702 further rigidifying the film at 3\%. 


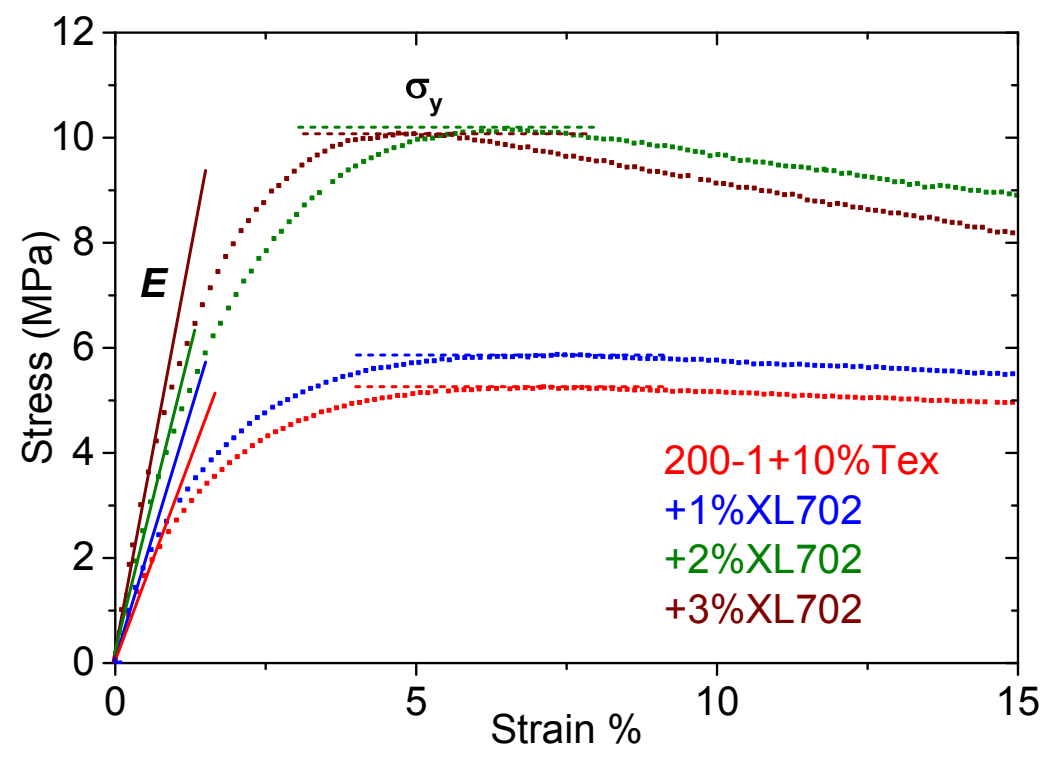

Fig. 14. Stress vs strain curves of the latex films $200-1+10 \%$ Tex with the crosslinker XL702 aged 3 days at $23^{\circ} \mathrm{C}$ and $75 \% \mathrm{RH}$.

\section{Table 7}

Tg, Young modulus $E$ and elastic limit $\sigma_{\mathrm{y}}$ for the films $200-1+10 \%$ Tex with the crosslinker XL702, aged 3 days $\left(23^{\circ} \mathrm{C}\right.$ and $\left.75 \% \mathrm{RH}\right)$.

\begin{tabular}{ccccc}
\hline Latex & $\mathbf{1 0 \%}$ Tex & $\begin{array}{c}+\mathbf{+ 1 \%} \\
\text { XL702 }\end{array}$ & $\begin{array}{c}+\mathbf{+ 2 \%} \\
\text { XL702 }\end{array}$ & $\begin{array}{c}+\mathbf{+ 3 \%} \\
\text { XL702 }\end{array}$ \\
\hline $\operatorname{Tg}\left(+/-1^{\circ} \mathrm{C}\right)$ & $20^{\circ} \mathrm{C}$ & $25^{\circ} \mathrm{C}$ & $30^{\circ} \mathrm{C}$ & $29^{\circ} \mathrm{C}$ \\
$E\left(10^{8} \mathrm{~Pa}\right)(+/-0.3)$ & 3.4 & 4.0 & 4.8 & 6.0 \\
$\sigma_{y}\left(10^{6} \mathrm{~Pa}\right)(+/-0.1)$ & 5.2 & 5.8 & 10.2 & 10.0 \\
\hline
\end{tabular}

\subsection{Influence of titanium oxide as a filler}

The last additive added to the latex $200-1+10 \%$ Tex was Tioxide (titanium oxide). Titanium oxide is used in latex paints as pigment or filler. In order to improve the dispersion and stabilization of titanium oxide in the latex, a little amount $(0.5 \mathrm{wt} \%)$ of thickener NaPAA was used in the formulation.

Fig. 15 shows the friction properties of the films measured with a sapphire indenter whose radius is large enough $(4.66 \mathrm{~mm})$ to allow the contact to be seen through the indenter (the films are opaque). The decrease in the friction coefficient at low confinement and the transition shift is the result of an increase in the film rigidity as explained previously. The increase of the mechanical properties of the films is due to the presence of inorganic particles which stiffened the films, here attested by the decrease of the maximum confinement. 


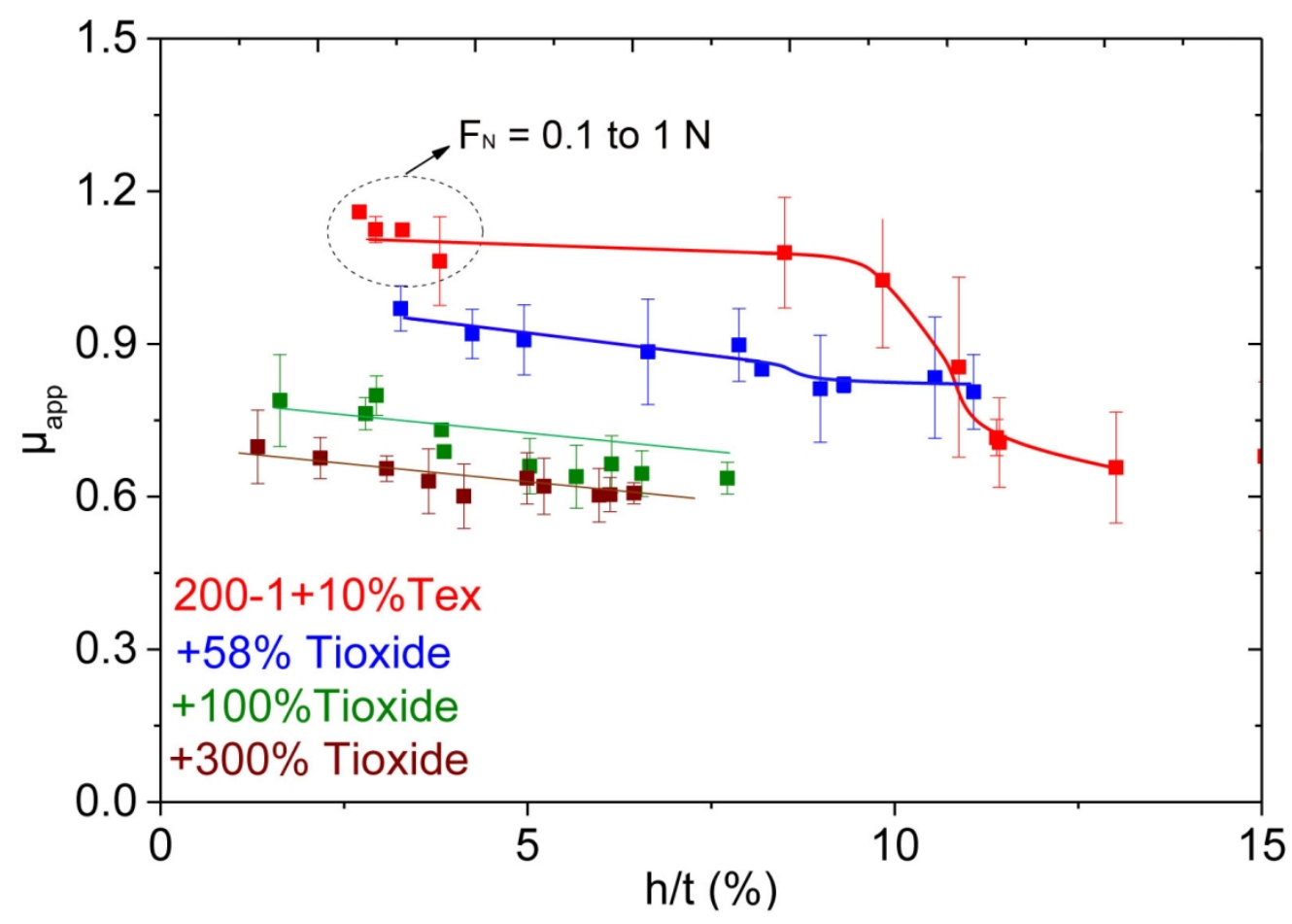

Fig. 15. Friction coefficient $\mu_{a p p}$ as a function of the confinement $\mathrm{h} / \mathrm{t}$ for the films $200-1+10 \%$ Tex with NaPAA $(0.5 \mathrm{wt} \%)$ and Tioxide $(58 \%, 100 \%$ and $300 \%)$ aged one day at $23^{\circ} \mathrm{C}$ and $75 \% \mathrm{RH}$. The normal load was increased from $1 \mathrm{~N}$ to $6 \mathrm{~N}$ (except for $200-1+10 \%$ Tex where the range was 0.1 to $6 \mathrm{~N}$ ). Sapphire indenter, $R=4.66 \mathrm{~mm}$.

\subsection{Summary}

Table 8 summarizes the main results of this study. Examination of the table makes appear a correlation between friction and bulk mechanical properties: the friction coefficient increases when the film softness increases and inversely. This is what can be expected. It is directly due to the "ploughing effect". The tip penetrates more in a softer film, creates a more important bulge and therefore its motion requires more energy. However, there is an exception in the case of the film containing the thickener (NaPAA). In this case, lubrication by the polyelectrolyte swollen by water dominates the contribution of the bulk of the film to friction energy. 
Table 8

Summary

\begin{tabular}{|c|c|c|c|c|}
\hline System & Variable & $\mu$ & $E, \mathbf{G}^{\prime}, \sigma_{\mathbf{y}}$ & Remark \\
\hline $\begin{array}{c}200-1 \\
\text { Initial latex film }\end{array}$ & $10 \%<\mathrm{RH}<75 \%$ & $\mu \uparrow$ & & $\begin{array}{c}\text { Film Softness } \uparrow \\
(\text { maximum confinement } \uparrow)\end{array}$ \\
\hline $\begin{array}{c}200-1+\text { plasticizer } \\
\text { (Tex) }\end{array}$ & $6 \%<$ Tex $<33 \%$ & $\mu \uparrow$ & $\mathrm{G}^{\prime} \downarrow$ & $\begin{array}{l}\text { Plasticizing effect much } \\
\text { stronger than by water }\end{array}$ \\
\hline $\begin{array}{l}\text { 200-1+10\%Tex } \\
\text { (Reference) }\end{array}$ & 1 day $<$ Aging $<100$ days & $\mu \downarrow$ & $E \uparrow, \sigma_{\mathrm{y}} \uparrow$ & $\begin{array}{l}\text { Very slow Texanol } \\
\text { evaporation }\end{array}$ \\
\hline $\begin{array}{l}200-1+10 \% \text { Tex } \\
+ \text { ethanol }\end{array}$ & $5 \%<\mathrm{EtOH}<25 \%$ & $\mu \uparrow$ & & $\begin{array}{c}\text { Film Softness } \uparrow \\
\text { (hypothesis) }\end{array}$ \\
\hline $\begin{array}{c}200-1+10 \% \text { Tex } \\
+ \text { thickener }\end{array}$ & $0.5 \%<\mathrm{NaPAA}<1.5 \%$ & $\mu \downarrow$ & $E \downarrow, \sigma_{\mathrm{y}} \downarrow$ & Lubrication \\
\hline $\begin{array}{c}200-1+10 \% \text { Tex } \\
+ \text { crosslinker }\end{array}$ & $1 \%<$ XL $702<3 \%$ & $\mu \downarrow$ & $E \uparrow, \sigma_{\mathrm{y}} \uparrow$ & Film Softness $\downarrow$ \\
\hline $\begin{array}{l}200-1+10 \% \text { Tex } \\
\quad+\text { pigment }\end{array}$ & $58 \%<\mathrm{TiO}_{2}<300 \%$ & $\mu \downarrow$ & & $\begin{array}{c}\text { Film Softness } \downarrow \\
\text { (maximum confinement } \downarrow \text { ) }\end{array}$ \\
\hline
\end{tabular}

\section{Conclusions}

It seemed interesting to us to investigate and present the individual effects of the main existing formulation additives before shifting to more complex systems. Obviously, completely formulated films should also be studied and it is a perspective for future work. When quantitative values on complex system are required, measurements will always be necessary. However, in some simple cases, friction behaviors can be qualitatively predicted knowing the findings of this article. For example, it is most likely that crosslinking and filler addition will cumulate their effects to lead to very low friction coefficients. Similarly, less plasticized films in drier environments will also present lower friction coefficients. More unpredictable are the systems with additives with opposite effects, like thickener plus filler. Friction will then depend on the relative amounts of the additives and on their distributions.

Indeed, distribution of components which tend to be heterogeneously distributed over the film thickness, for instance over-concentrated at the surface, is a crucial issue in friction studies (like in adhesion, adhesion and friction sharing many common aspects). This is possibly the case with a thickener. Another important example is the case of the surfactant, not tackled in the present work [21]. Distributions of components like surfactants in latex films was extensively studied, experimentally, by modelling and by simulation $[10,50]$. It is one of the numerous problems needed to be solved before real predictive quantitative approaches can be envisioned in the field of friction properties of thin polymeric films.

\section{Acknowledgements}

We thankfully acknowledge helpful discussions with Dr. L. Ruhaut, Mr. F. Pagnac and Mr. J.L. Vincent (SAR Company). The financial support to the PhD work of one of us (V.D.) by the French Company "Société d'Applications Routières" (SAR) is gratefully acknowledged. 


\section{References}

[1] N. Delorme, M.S. Chebil, G. Vignaud, V. Le Houerou, J.F. Bardeau, R. Busselez, A. Gibaud, Y. Grohens, Experimental evidence of ultrathin polymer film stratification by AFM force spectroscopy, Eur. Phys. J. E 38 (2015) 56.

[2] H. Zeng, Polymer Adhesion, Friction, and Lubrication, Wiley, 2013.

[3] E. Gnecco, E. Meyer, Fundamentals of Friction and Wear on the Nanoscale, Springer, 2015.

[4] L.H. Lee, Advances in Polymer Friction and Wear, Springer, 1974.

[5] K. Holmberg, A. Matthews, Coatings Tribology: Properties, Mechanisms, Techniques and Applications in Surface Engineering, Elsevier, 2009.

[6] S. Lafaye, C. Gauthier, R. Schirrer, A surface flow line model of a scratching tip: apparent and true local friction coefficients, Tribol. Int. 38 (2005) 113-127.

[7] H. Zeng, J. Huang, Y. Tian, L. Li, M.V. Tirrell, J.N. Israelachvili, Adhesion and detachment mechanisms between polymer and solid substrate surfaces using polystyrene-mica as a model system, Macromolecules 49 (2016) 5223-5231.

[8] E. Gacoin, C. Fretigny, A. Chateauminois, A. Perriot, E. Barthel, Measurement of the mechanical properties of thin films mechanically confined within contacts, Tribol. Lett. 21 (2006) 245-252.

[9] E. Gacoin, A. Chateauminois, C. Fretigny, Measurements of the viscoelastic moduli of an acrylate polymer in bulk and in film form using a contact method, Polymer 45 (2004) 3789-3796. [10]J. Keddie, A. Routh, Fundamentals of Latex Film Formation: Processes and Properties, Springer: Dordrecht. The Netherlands, 2010.

[11]H.M. van der Kooij, G.T. van de Kerkhof, J. Sprakel, A mechanistic view of drying suspension droplets, Soft Matter 12 (2016) 2858-2867.

[12] M. Vischers, J. Laven, A.L. German, Current understanding of the deformation of latex particles during film formation, Prog. Org. Coat. 30 (1997) 39-49.

[13] C. Gauer, H. Wu, M. Morbidelli, Effect of surface properties of elastomer colloids on their coalescence and aggregation kinetics, Langmuir 25 (2009) 12073-12083.

[14] V. Divry, A. Gromer, M. Nassar, C. Lambour, D. Collin, Y. Holl, Drying Mechanisms in Plasticized Latex Films: Role of Horizontal Drying Fronts, J. Phys. Chem. B 120 (2016) 6791-6802.

[15] H.M. van der Kooij, R. Fokkink, J. van der Gucht, J. Jasper, Quantitative imaging of heterogeneous dynamics in drying and aging paints, Sci. Rep. 6 (2016) 34383.

[16] J. Domnick, D. Gruseck, K. Pulli, A. Scheibe, Q. Ye, F. Brinckmann, Investigations of the drying process of a water based paint film for automotive applications, Chem. Eng. Proc. 50 (2011) 495-502.

[17] J.C. Padget, Polymers for water-based coatings - A systematic overview, J. Coat. Technol. 66 (1994) 89-105.

[18] T. Robert, Green ink in all colors-Printing ink from renewable resources, Prog. Org. Coat. 78 (2015) 287-292.

[19] R. Jovanovic, M.A. Dube, Emulsion-based pressure-sensitive adhesives: A review, J. Macromol. Sci.-Polym. Rev. C44 (2004) 1-51. 
[20] G. Tiwari, R. Tiwari, B. Sriwastawa, L. Bhati, S Pandey, P Pandey, S.K. Bannerjee, Drug delivery systems: An updated review, Int. J. Pharm. Investig. 2 (2012) 2-11.

[21] G. Klein, V. Le Houérou, C. Gauthier, Y. Holl, Friction properties of acrylic-carboxylated latex films. 2: Effect of post added surfactant, Tribol. Int. 57 (2013) 257-265.

[22] C. Bjerremand, J; Larsen, M. Hinge, Temperature- and time dependency on high friction poly(styrene-co-butyl methacrylate) coated paper, Tribol. Int. 103 (2016) 261-265.

[23] W. Anancharungsuk, W. Taweepreda, S. Wirasate, R. Thonggoom, P. Tangboriboonrat, Reduction of Surface Friction of Natural Rubber Film Coated with PMMA Particle: Effect of Particle Size, J. Appl. Polym. Sci. 115 (2010) 3680-3686.

[24] G. Klein, V. Le Houérou, R. Muller, C. Gauthier, Y. Holl, Friction properties of acryliccarboxylated latex films. 1: Effects of acrylic acid concentration and pH, Tribol. Int. 53 (2012) $142-149$.

[25] F. Belaroui, M.P. Hirn, Y. Grohens, P. Marie, Y. Holl, Distribution of Water-Soluble and Surface-Active Low-Molecular-Weight Species in Acrylic Latex Films, J. Colloid Interface Sci. 261 (2003) 336-348.

[26] V. Divry, Formation Mechanisms and Structure/Property Relationships in Fast Drying Latex Films, Ph.D. Thesis, University of Strasbourg, France, 2016.

[27] A. Toussaint, M. De Wilde, F. Molenaar, J. Mulvihill, Calculation of Tg and MFFT depression due to added coalescing agents, Prog. Org. Coat. 30 (1997) 179-184.

[28] N. Nakajima, Y. Ikada, Mechanism of amide formation by carbodiimide for bioconjugation in aqueous-media, Bioconjugate Chem. 6 (1995) 123-130.

[29] C. Gauthier, R. Schirrer, Time and temperature dependence of the scratch properties of poly(methylmethacrylate) surfaces, J. Mater. Sci. 35 (2000) 2121-2130.

[30] A. Rubin, C. Gauthier, R. Schirrer, Analysis of the effect of nano-roughness on the friction of a vitreous polymer, Wear 303 (2013) 40-48.

[31] D. Collin, R. Covis, F. Allix, B. Jamart-Grégoire, P. Martinoty, Jamming transition in solutions containing organgelator molecules of amino-acid type: rheological and calorimetry experiments, Soft Matter 9 (2013) 2947-2958.

[32] R.S. Gurney, A. Morse, E. Siband, D. Dupin, S.P. Armes, J.L. Keddie, Mechanical properties of a waterborne pressure-sensitive adhesive with a percolating poly(acrylic acid)-based diblock copolymer network: Effect of pH, J. Coll. Interf. Sci. 448 (2015) 8-16.

[33] M. Chenal, J. Rieger, C. Véchambre, J.M. Chenal, L. Chazeau, C. Creton, L. Bouteiller, Highly Ordered Non-Equilibrium Nanostructures from RAFT Polymerized Emulsions, Macromol. Rapid Comm. 34 (2013) 1524-1529.

[34] X. Cai, H. Bangert, Hardness measurements of thin films-determining the critical ratio of depth to thickness using FEM, Thin Sol. Film 264 (1995) 59-71.

[35] S. Zohrehvand, K. te Nijenhuis, Film formation from monodisperse acrylic latices. Drying and ageing in coalescing agent containing latex films, J. Colloid Interface Sci. 288 (2005) 75-82.

[36] W.F. Schroeder, Y. Liu, J.P. Tomba, M. Soleimani, W. Lau, M.A. Winnik, Effect of a coalescing aid on the earliest stages of polymer diffusion in poly(butyl acrylate-co-methyl methacrylate) latex films, Polymer 52 (2011) 3984-3993.

[37] M. Gallagher, P. Dalton, L. Sitvarin, G. Preti, Sensory and analytical evaluations of paints with and without Texanol, Environ. Sci. Technol. 42 (2008) 243-248.

[38] J. Holten-Andersen J., C.M. Hansen, Solvent and water evaporation from coatings, Prog. Org. Coat. 11 (1983) 219-240. 
[39] Z. W. Wicks, F.N. Jones, S. P. Papas, Organic Coatings: Science and Technology, J. Wiley, 1992.

[40] G. Reiter, Probing Properties of Polymers in Thin Films Via Dewetting, Adv. Polym. Sci. 252 (2013) 29-63.

[41] C. Bindschaedler, R. Gurny, E. Doelker, N.A. Peppas, Thermodynamics of Swelling of Polymer Latex Particles by a water-soluble solvent: Theoretical Considerations, J. Colloid Interface Sci. 108 (1985) 75-82.

[42] R. Popli, M.H. Luccas, S.L. Tsaur, Swelling of Latex Particles by Water-Soluble Solvents: Experimental Results, Langmuir 7 (1991) 69-72.

[43] R.E. Dillon, E.B. Bradford, R.D.J. Andrews, Plasticizing a Synthetic Latex, Ind. Eng. Chem. 45 (1953) 728.

[44] M. Joanicot, K. Wong, J. Richard, J. Maquet, B. Cabane, Ripening of Cellular Latex Films, Macromolecules 26 (1993) 3168-3175.

[45] F. Belaroui, B. Cabane, M. Dorget, Y. Grohens, P. Marie, Y. Holl, Small-angle neutron scattering study of particle coalescence and SDS desorption during film formation from carboxylated acrylic latices, J. Colloid Interface Sci. 262 (2003) 409-417.

[46] D. Graebling, R. Muller, J.F. Palierne, Linear viscoelastic behavior of some incompatible polymer blends in the melt. Interpretation of data with a model of emulsion of viscoelastic liquids, Macromolecules 26 (1993) 320-329.

[47] J.Y. Charmeau, R. Berthet, C. Gingreau, E. Kientz, Y. Holl, Effect of film structure on mechanical and adhesion properties of latex films, Int. J. Adhesion Adhesives 17 (1997) 169-176.

[48] M. Beauvais, B. Piezel, F. Hamidi, M. Villalobos, C. Da Silva, E. Martin, D. Dalmas, E. Barthel, Film formation mechanism in glass lubrication by polymer latex dispersions, Thin Solid Films, 518 (2010) 1689-1697.

[49] V.S. Ajaev, E.Y. Gatapova, O.A. Kabov, Stability and break-up of thin liquid films on patterned and structured surfaces, Adv. Colloid Interface Sci. 228 (2016) 92-104.

[50] A. Gromer, F. Thalmann, P. Hébraud, Y. Holl, Simulation of Vertical Surfactant Distributions in Drying Latex Films, Langmuir 33 (2017) 561-572. 